\title{
The Determinants of Stock Returns in a Small Open Economy*
}

\author{
Séverine CAUCHIE \\ HEC-University of Geneva \\ Martin HOESLI* \\ University of Geneva (HEC and FAME) and University of Aberdeen (Business School) \\ Dušan ISAKOV \\ HEC-University of Geneva and International Center FAME
}

This draft: May 27, 2003

\begin{abstract}
This paper examines the determinants of stock returns in a small open economy using an APT framework. The analysis is conducted for the Swiss stock market which has the particularity of including a large proportion of firms that are exposed to foreign economic conditions. Both a statistical and a macroeconomic implementation of the model are performed for the period 1986-2002 with monthly returns on industrial sector indices. The results show that the statistically determined factors yield a better representation of the determinants of stock returns than the macroeconomic variables and that stock returns are influenced by both global and local economic conditions. This suggests that the Swiss stock market is an internationally imperfectly integrated market.
\end{abstract}

Keywords: Statistical APT; Macroeconomic APT; Market integration; Risk factors JEL Classification : G12; G15

\footnotetext{
* We are grateful to three anonymous referees, Michel Dubois, Christophe Pérignon, Patricia Fraser, Guido Bolliger and seminar participants at the 5th Conference of the Swiss Society for Financial Market Research in Basle for valuable comments. Isakov's research is carried out within the National Centre of Competence in Research "Financial Valuation and Risk Management." (NCCR FINRISK). The NCCR FINRISK is a research programme supported by the Swiss National Science Foundation. We alone remain responsible for any remaining errors.

*Address for correspondence: Martin Hoesli, University of Geneva, HEC, 40 Boulevard du Pont-d'Arve, CH1211 Geneva 4, Switzerland, Phone: +41 22705 8122, Fax: +41 22705 8104, Email: martin.hoesli@hec.unige.ch
} 


\section{The Determinants of Stock Returns in a Small Open Economy}

\section{Introduction}

Identifying the forces that drive stock returns is a major concern for practice and academic research. Financial theory provides several asset pricing models that relate expected returns to one or several variables representing various sources of risk. The identity of these variables depends on the assumptions on which the model is built. The most popular asset pricing models are the Capital Asset Pricing Model, CAPM (one source of risk) and the Arbitrage Pricing Theory, APT (several sources of risk). Such models are used e.g. to assess the performance of managed funds or measure the cost of capital.

Early versions of these models were developed under the assumption that investors have access to domestic securities only. This is a reasonable assumption if agents live in a closed economy or if a given country's financial market is totally segmented from other markets. These models have been tested extensively in the financial economics literature, but tests of the CAPM are at best unconvincing, and several "anomalies" have been reported. As factors are not explicitly specified by theory, two empirical versions of the APT have been implemented: factors are either extracted by means of statistical techniques or are prespecified. In their seminal paper, Chen et al. (1986) consider the influence of a set of six prespecified macroeconomic U.S. variables and find that three such factors are priced for the U.S. stock market. A number of authors have taken the same approach for various stock markets (e.g. Hamao, 1988, for Japan; Antoniou et al., 1998, for the U.K.).

In another class of models, the assumption of investment being solely domestic is relaxed. In such a context, markets are assumed to be perfectly integrated because of the presence of arbitrageurs that trade stocks internationally. Such trading equalizes the price of stocks with the same payoffs across markets. This has led to the extension of domestic pricing models to international models, such as the various versions of the international CAPM or the international APT. Typically, the world market portfolio and the foreign exchange risk are considered as global sources of risk in the international CAPM (e.g. Korajczyk and Viallet, 
1989), whereas various global factors are hypothesized to impact on stock prices in the international APT (e.g. Ferson and Harvey, 1994). Empirical evidence pertaining to these models is mixed (for surveys, see Heston et al., 1995; Karolyi and Stulz, 2003). As such models rely on the joint hypothesis of the validity of the model and of the perfect integration of international stock markets, it is impossible, however, to attribute rejection to any one of the two assumptions.

In an era of increasing globalization, it seems reasonable to assume that most developed markets would be integrated. The empirical international asset pricing literature suggests that this is unlikely to be the case, and that most markets are in fact imperfectly integrated. For instance, country effects have been shown to dominate industry effects (Heston and Rouwenhorst, 1994). Further, Griffin and Karolyi (1998) find that industries with internationally traded goods are more sensitive to global industry factors than firms that produce goods that are only domestically traded. Griffin and Stulz (2001) and Fedorov and Sarkissian (2000) also conclude that companies or industries with internationally traded goods are more integrated due to the cash flows of such firms being more sensitive to global factors. Finally, there is clear evidence that investors do not diversify their portfolios internationally as much as is suggested by portfolio theory. This phenomenon is known as the home bias and is a well-known anomaly in the international finance literature (for a review, see Lewis, 1999). This bias is the sign of the existence of market imperfections that prevent investors from diversifying their portfolio in an optimal way. Besides barriers to international investments, there are also additional costs related to such investments. These results constitute evidence against the assumption of perfect international market integration. In this case, pure international asset pricing models may not constitute a good representation of reality.

Given this, theoretical asset pricing models assuming partial integration would appear to be better suited to explain stock returns. Such models provide a pricing equation both for securities that can and for securities that cannot be held by foreign investors (Errunza and Losq, 1985; Hietala, 1989; and Cooper and Kaplanis, 2002). However, these models neither offer any indication on how to measure the level of integration of a specific market, nor do they provide a general equilibrium relationship that can be used for international asset pricing. Given the lack of theoretical guidance, some authors have used a more empirical approach in that they include both local and global variables in the pricing equation; the relative 
importance of such factors being weighted by the degree of integration of the market (Bekaert and Harvey, 1995; Hardouvelis et al., 2002). Yet another approach that has been used is to add a single international variable (exports, a world index or the foreign exchange rate) to a domestic APT model with pre-specified macroeconomic variables. Examples include Martikainen, Yli-Olli and Gunasekaran (1991) for Finland, Kryzanowski and Zhang (1992) for Canada, Clare and Thomas (1994) for the U.K., Kaneko and Lee (1995) for Japan, Groenewold and Fraser (1997) for Australia, and Clare and Priestley (1998) and Bilson et al. (2001) for emerging markets. We are aware of one study which has used several pre-specified local and global factors, but for emerging markets only (Rendu de Lint, 2002).

Following up on this literature, this paper assumes explicitly that the determinants of stock returns can be either local, global or a combination of both. As risk is likely to be multidimensional, the aim of this paper is to identify empirically the determinants of stock returns by using techniques that have been devised to implement and test the APT. This paper focuses on the Swiss stock market for the following important reason. As can be seen from Table 1, Switzerland belongs to a group of countries with developed stock markets that have a very large fraction of their quoted companies doing business abroad. Among these, only the Netherlands, Hong Kong, Finland, and Sweden have a larger exposition to international trade. Switzerland is the ninth largest stock market in the world and more than $80 \%$ of its companies have overseas sales. More than $50 \%$ of sales are foreign sales on average. This is in sharp contrast with results for the U.S., for instance, where these figures amount to $31 \%$ and $10 \%$, respectively. Additionally, there are no limitations to foreign ownership of stocks of Swiss companies. This would clearly speak for the integration of the Swiss market. Despite the international dimension of the Swiss stock market, it is one of the few developed markets that has been found not to be integrated (Heston et al., 1995). This is puzzling and the Swiss market is therefore an ideal candidate for using an approach with both local and global factors. Moreover, the Swiss market has been the focus of limited research only. The extant literature for Switzerland suffers from drawbacks as it has considered domestic factors only (Cuenot and Reyes, 1992; Beckers et al., 1993; Vessereau, 2000), or used a limited sample of stocks (Broillet, 1991), or a very short time period (Gallati, 1993).

This paper makes the following contributions. First, it distinguishes itself from the extant literature by considering the influence on stock returns of both global and local variables for a developed market where most of the firms are internationally oriented. Second, the 
determinants are obtained from a broad set of variables representing macroeconomic influences on financial markets. These variables represent the evolution of economic conditions in Switzerland and in countries of the G7, the major trade partners of Switzerland. They can be classified in the following broad groups: business cycle, inflation, interest rates, and financial markets. These variables are all related to expected cash flows and/or discount rates, and therefore to stock prices. The selection of variables is made endogenously, starting from a large set of potential determinants, and then finding the best set of variables by means of cluster analysis. From a methodological point of view, the paper also provides significant improvements. It extends the methodology of Pettengill et al. (1995) to a multi-factor setting to assess the significance of the risk premia both for positive and negative occurrences of the factors. As our paper is set in an APT framework, variables should be represented by innovations. Among the methods used to determine such innovations, the most popular methods are the first differences and the ARIMA-type adjustments. We use an alternative approach in that we compute innovations using Kalman filters. Priestley (1996) shows that such an approach leads to more reliable inferences regarding tests and applications of the APT. Finally, the best set of macroeconomic variables is compared to statistical factors. The latter are extracted using a technique recently proposed by $\mathrm{Xu}$ (2003) that assumes heteroskedasticity both in time series and in cross section.

The empirical investigation is conducted on a set of portfolios representing the industrial sectors of the Swiss stock market to avoid the noise associated with individual stocks and to capture the major macroeconomic influences on the stock market. The results of our paper confirm our hypothesis that the Swiss stock market is influenced by both local and global factors. Four macroeconomic variables emerge from the analysis, two of which being related to global economic conditions and two reflecting domestic influences. A pure statistical approach yields five factors with a high explanatory power. These factors appear to be related to both global and local macroeconomic variables, providing further support for the partial integration of the Swiss stock market. This result has important practical implications in that both types of factors should be considered e.g. for hedging purposes, performance measurement and cost of capital computations.

The remainder of the paper is organized as follows. Section 2 presents the method used, while section 3 introduces our data. Section 4 presents the results of our empirical analysis. Finally, section 5 contains some concluding remarks. 


\section{Method}

\subsection{The two-pass method}

We test the validity of the two fundamental pricing relations with the well-known technique initially proposed by Fama and MacBeth (FM, 1973) ${ }^{1}$ to test the CAPM. To implement this type of test, we first divide the period January 1986-November 2002 into 144 overlapping periods of five years to estimate the factor sensitivities. Each period contains 60 monthly returns on 19 industrial portfolios. The first period begins in January 1986 and ends in December 1990. The second also covers a five-year interval but begins (and ends) one month later (February 1986-January 1991). The last period begins in December 1997 and ends in November 2002.

The first step of the FM method involves the estimation of the portfolio sensitivities (risk coefficients) to each factor. This is done for every five-year period and the sensitivities are the coefficients obtained from a time-series regression of the portfolio returns on the factor realizations as described in equation (1):

$$
r_{p t}=\beta_{p 0}+\sum_{j=1}^{K} \beta_{p j} F_{j t}+\varepsilon_{p t}
$$

where $r_{p t}$ is the observed return on industrial portfolio $p$ in month $t(p=1, \ldots, 19$ and $t=1, \ldots, 60), \beta_{p 0}$ represents the constant term, $\beta_{p j}$ symbolizes portfolio $p$ sensitivity to factor $j$ which is either a factor loading or a macroeconomic variable, $F_{j t}$ is the observed value of factor $j$ in month $t$ and $\varepsilon_{p t}$ represents the residual error term that is assumed to be normally, identically and independently distributed. In our specific case, we have sensitivities to either macroeconomic variables or to statistical factors depending on the type of APT model that we implement.

In a second step, we use the estimates of the sensitivities as independent variables in the cross-sectional regression described in equation (2):

\footnotetext{
${ }^{1}$ Since its inception, this technique has been widely used in tests of asset pricing models (e.g. Brennan et al., 1998 and Fama and French, 1992).
} 


$$
r_{p t}-r_{f t}=\lambda_{o t}+\sum_{j=1}^{K} \lambda_{j t} \hat{\beta}_{p j}+u_{p t}
$$

where $r_{f t}$ is the risk free rate proxied by the one-month interbank offered rate, $\hat{\beta}_{p j}$ symbolizes portfolio $p$ estimated sensitivity to factor $j, \lambda_{o t}$ represents the intercept, $\lambda_{j t}$ is the estimated risk premium for factor $j$ in month $t, u_{p t}$ represents the residual error term with usual assumptions. This procedure yields estimates of the risk premia for the different factors for month $t$.

We run this regression on the portfolios' excess returns for the month following the five-year period over which the sensitivities are estimated and obtain a time series of 144 estimates of the risk premia (from 1991 to 2002) for each factor included in the model. We then test if the mean of each series is statistically different from zero with three different estimators of its standard deviation: (1) the GMM estimator that is robust to departures from normality, (2) the Newey and West (1987) correction for autocorrelation and heteroskedasticity, and (3) the Shanken (1992) correction for error-in-variables. If the mean of each series is statistically different from zero, it indicates that the considered risk factor is priced.

As always, the cross-sectional regressions test for a relationship between sensitivities and realized returns, whereas the $\mathrm{APT}$ is expressed in terms of expected returns. Most of the empirical literature on the CAPM reports the absence of a statistical relationship between risk and realized return. Several authors have advocated that this is due to the use of realized in lieu of expected returns. This distinction leads to a testing procedure that distinguishes between bull and bear markets, hypothesizing a positive risk-return relationship in upward markets and a negative relationship in downward markets. This approach was initially developed by Pettengill et al. (1995) who found conclusive evidence for the U.S. ${ }^{2}$ The discrepancy between tests using realized returns and expectation-based theoretical models also exists for APT-type models. For this reason, we extend the Pettengill et al. approach to the multi-factor framework and estimate the following relationship between portfolio excess returns $\left(r_{p t}-r_{f t}\right)$ and factor sensitivities $\left(\beta_{p t}\right)$ :

$$
r_{p t}-r_{f t}=\lambda_{o t}+\sum_{j=1}^{K} \lambda^{+}{ }_{j i} \hat{\delta}_{j} \hat{\beta_{p j}}+\sum_{j=1}^{K} \lambda^{-}{ }_{j t}\left(1-\delta_{j}\right) \hat{\beta_{p j}}+u_{p t}
$$

\footnotetext{
${ }^{2}$ These results have been confirmed for other countries (see e.g. Fletcher, 1997, for the U.K., Isakov, 1999, for Switzerland, Hodoshima et al. for Japan, 2000, and Elsas et al., 2003, for Germany).
} 
where $\lambda_{o t}$ represents the intercept, $\lambda_{j t}^{+}\left(\lambda^{-}{ }_{j t}\right)$ is the estimated risk premium for factor $j$ conditional on a positive (negative) realization of factor $j$ in month $t, \delta_{j}$ is a dummy variable equal to 1 when factor $j$ is positive and equal to 0 otherwise and $u_{p t}$ represents the residual error term with usual assumptions.

As in the standard FM method, we obtain time-series for the $\lambda_{o t}, \lambda_{j t}^{+}, \lambda^{-}{ }_{j t}$ coefficients. We then test whether $\lambda_{o t}$ is on average equal to zero, $\lambda_{j t}^{+}$is on average positive and $\lambda_{j t}^{-}$is on average negative. Finally, we test if the positive mean is statistically different from the negative one in absolute value to check if the risk premia behave symmetrically.

\subsection{Statistical APT}

Among the various methodologies that are available to extract the factors underlying asset returns, we use a new method proposed by Xu (2003), the Maximum Explanatory Component Analysis. It is a standard principal component analysis applied to the correlation matrix of returns which derives factors by maximizing their explanatory power across assets. These factors are obtained by taking into account the presence of heteroskedasticity over time and across assets. Contrary to what is the case with factor analysis, this method does not suffer from a scaling issue nor from a rotation problem ${ }^{3}$.

To determine the relevant number of statistical factors to be used in the two-pass FM method, we use the technique developed by Connor and Korajczyk (1993). This procedure assumes that if asset returns are described by a $K$-factor structure, the addition of a factor can be important for some assets but not necessary for a large proportion of them. This proposition is formally tested by comparing the cross-sectional average of squared residuals $\eta_{t}^{K}=\left(\varepsilon_{t}{ }^{\prime} \varepsilon_{t}^{K}\right) / N$ for models containing $K$ and $K+1$ factors, respectively, at time $t$. The statistic $\hat{\Delta}_{t}^{K, K+1}=\eta_{t}^{K}-\eta_{t}^{K+1}$ measures the difference between the cross-sectional averages of squared residuals with $K$ and $K+1$ factors, respectively. As it has been shown that the distribution of $\hat{\Delta}_{t}^{K, K+1}$ degenerates under the null hypothesis of a K-factor structure, Connor and Korajczyk (1993) propose to use

\footnotetext{
${ }^{3}$ This is also true for standard principal component analysis (PCA). For this reason, most of the empirical investigations of the APT favor PCA (see e.g. Brennan et al., 1998 and Merville et al., 2001).
} 
an alternative statistic which compares the average squared residuals in one period (at time $s$ 1) with the average squared residuals in the next period (at time $s$ ):

$$
\hat{\Delta}_{s}^{K, K+1}=\eta_{s-1}^{K}-\eta{ }_{s}^{K+1}
$$

As this statistic is computed over non-overlapping periods, there are $T / 2$ observations. In our case we have 102 observations for this statistic since the test is run over the January 1986December 2002 whole sample period (204 months). The final statistic $\bar{\Delta}_{K, K+1}$ is the mean of the time series of $\hat{\Delta}_{s}^{K, K+1}$ and it follows asymptotically a t-distribution with $T / 2$ degrees of freedom. If an additional factor is relevant to explain asset returns, the difference in average squared residuals is significant and the null hypothesis is rejected. We select the optimal number of statistical factors as being equal to $K+1$, with $K$ being the largest value for which the null is rejected at the $5 \%$ level. Finally, to account for the fact that estimated statistical factors are used instead of true factors, a degrees of freedom correction is necessary and the statistic is based on an adjusted squared residuals defined as $\hat{\xi_{t}^{K}}=\hat{\varepsilon}_{t}^{K} / \sqrt{(1-(K+1) / T-K / N)}$ instead of $\varepsilon_{t}^{K}$.

\subsection{Macroeconomic APT}

As is the case with the statistical model, we need to determine the number and identity of relevant pre-specified factors before estimating the pricing model. The method proposed by Mei (1993) is used to find out the number of factors. He shows that a $K$-factor model can be transformed into a $K$-lag autoregressive model. Therefore, if $K$-lagged returns are sufficient to explain the cross-section of asset returns, we can conclude that the factor structure consists of $K$ factors. To implement this test, we estimate models containing from ten to one lags on each of the 19 portfolios. For each lag examined, we compute a generalized sum of squared residuals $\left(Q_{K}\right.$ where $K$ represents the number of lags considered). Then, we compute the difference $\left(L_{K, K+1}\right)$ between $Q_{K}$ and $Q_{K+1}$ (which contains one more lag). This difference measures the reduction of the generalized sum of squared residuals that results from including an additional lag. Under the null hypothesis that $L_{K, K+1}$ is not reduced by an additional lag, $L_{K, K+1}$ follows a Chi-square distribution. The number of degrees of freedom is equal to the difference between the number of parameters estimated in the model with $K$ lags and the model with $K+1$ lags (204 in our case). The number of factors is equal to $K+1$ for the first $\mathrm{K}$ which rejects the null hypothesis. This test is performed over the whole period (1986-2002). 
The variable selection is undertaken using cluster analysis. This statistical technique permits to group data in such a way that observations belonging to the same cluster present similarities, whereas observations in separate clusters exhibit substantial differences. We use an agglomerative hierarchical clustering algorithm that starts with as many groups as there are variables and that computes dissimilarities between groups in terms of modified Euclidean distance. We select a procedure that merges groups at a distance that is the maximum between initial distances. This technique allows us to determine $K$ groups of variables from which the factors needed for the implementation of the macroeconomic model are selected. We assume that variables belonging to the same group are substitutes to one another, which means that any variable within each cluster can be considered to be representative of that cluster. As a result, several alternative macroeconomic versions of the APT are investigated.

All macroeconomic models are then estimated through the FM two-pass method. To find which model best fits the cross-section of returns, we combine two criteria: the model explanatory power $\left(R^{2}\right)$ and the stability of this measure through time. Our idea is that the best macroeconomic model should be able to explain the cross-section of portfolio returns not only a few times, but in a consistent way. We establish the ranking of the model by means of a synthetic index $I=\frac{1}{2}\left(I_{R^{2}}+I_{R_{A}^{2}}\right)$. The component $I_{R^{2}}$ is the ratio of the average $R^{2}$ of the macroeconomic model over the standard deviation of the $R^{2}$ :

$$
I_{R^{2}}=\frac{\bar{R}^{2}}{\sigma_{R^{2}}}
$$

$I_{R_{A}^{2}}$ is constructed in the same way using the adjusted $R^{2}\left(R_{A}^{2}\right)$ instead of the $R^{2}$ in equation (5). We combine these two measures as they do not yield the same ranking of models and as both provide reasonable measures of the fit of the model.

\subsection{Comparison of models}

We use the tests proposed by Chen and Jordan (1993) and Chen et al. (1997) to investigate the similarities between the risk premia from statistical and macroeconomic models and to compare the explanatory power of both types of models. 
An analysis of the similarities between macroeconomic and statistical risk premia allows us to check if the selected macroeconomic factors correspond to factor loadings, therefore providing an economic content to statistically generated factors. For this purpose, two methods are used: multiple regression analysis and correlation analysis. We regress each statistical risk premium on all macroeconomic risk premia and analyze the significance of coefficients. We also provide evidence on univariate dependences between the various risk premia by analyzing the correlation matrix of all risk premia (statistical and macroeconomic $)^{4}$.

Our second concern is to determine which model provides the most accurate description of Swiss stock returns by comparing the cross-sectional adjusted $R^{2}$ s by means of a Wilcoxon matched-pairs signed-rank test. The null hypothesis is that the median of the distribution of the difference between both time-series of adjusted $R^{2} \mathrm{~s}$ is equal to zero. As the distribution of the adjusted $R^{2}$ s is unknown, we use a non-parametric procedure that relies on the Wilcoxon z-statistic. As our sample contains 144 observations, the test compares the z-statistic to a normal distribution.

The Davidson and MacKinnon procedure (1981) is another procedure to assess which model has more power in explaining the cross-section of portfolio returns. To perform the test, we use time-series of forecasted returns for each portfolio. The forecasted series are obtained with estimates of the statistical model and with estimates of the macroeconomic model. For each month $t$ of the validation period (1991-2002), we use a cross-section of forecasted returns as regressors:

$$
r_{P, t}=\theta_{t} \hat{r}_{s, t}+\left(1-\theta_{t}\right) \hat{r}_{M, t}+\varepsilon_{t}
$$

where $\hat{r}_{s, t}$ is a cross-section of returns forecasted with the statistical model at time $t$ and $\hat{r}_{M, t}$ is a cross-section of returns forecasted with the macroeconomic model at time $t$. After having estimated this equation for the 144 months of the validation period, we compute the mean of the regression coefficient $\overline{\hat{\theta}}$ and its standard deviation to formally test with a t-test if $\overline{\hat{\theta}}=0.5$, i.e. if one model explains the portfolio returns better than the other. Note that the sign of this statistic indicates which model dominates the other. In this particular case, if the t-statistic, i.e. $(\overline{\hat{\theta}}-0.5) / \hat{\sigma}(\overline{\hat{\theta}})$, is positive, it means that the macroeconomic model is less powerful than

\footnotetext{
${ }^{4}$ Canonical correlations were also considered and yielded similar conclusions.
} 
the statistical one. On the contrary, a negative t-statistic indicates that the macroeconomic version of the APT is a better model.

\section{Data}

To capture the fundamental forces that drive stock returns and to avoid the noise of individual stock data, we use portfolios representing the industrial sectors of the Swiss stock market. These are the most disaggregated sub-sector total return indices as provided by Datastream Thomson Financial (aggregation level 6). Monthly continuously compounded returns are computed for the period 1986-2002. The choice of using a monthly frequency is dictated by the frequency of macroeconomic variables. Such data were not available before 1986. The dataset encompasses 18 industrial portfolios weighted by market capitalization and a $19^{\text {th }}$ portfolio that contains all sub-sector indices for which no complete performance history is available. Table 2 presents summary statistics for the 19 portfolios.

\section{[Insert Table 2]}

Over the whole period, the market index yielded an average monthly return of $0.65 \%$ and a standard deviation of $5.28 \%$. Table 2 shows that these parameters vary quite substantially across industries. The skewness and kurtosis statistics are in line with those reported in previous research and they show that return distributions are slightly asymmetric and have fatter tails than the normal distribution. To take this deviation from normality into account, we use GMM estimators (for more details on this, see Groenewold and Fraser, 2001).

The Swiss economy being small, heavily involved in international trade and likely to be imperfectly integrated, both domestic and foreign factors should impact on the expected cash flows and discount rates of Swiss companies and therefore on stock returns. All macroeconomic variables are extracted from Datastream Thomson Financial. For the international variables, we use data pertaining to the G7 countries as Switzerland does most of its trade with these countries. These are constructed by weighting each country's deseasonalized variable by its relative GDP.

The choice of potential macroeconomic risk factors is based on the idea of Chen et al. (1986). They argue that any economic force that systematically affects the stream of future cash flows and/or the discount rate will have an impact on prices and hence on returns. Our 
macroeconomic variables can be classified into four broad groups. The first group represents variables that are linked to the general level of activity. A number of studies have documented a relationship between current production and stock returns (Fama, 1981; Schwert, 1990). The variables used to measure the level of activity are: unemployment (both in Switzerland and in the G7), Swiss retail sales, Swiss exports, and G7 industrial production ${ }^{5}$. As Switzerland does not produce oil, it is forced to import this resource; we assume therefore that oil prices have an impact on the Swiss economy and use the Brent oil index. This is consistent with papers by Chen et al. (1986) and Clare and Thomas (1994). Finally, this group of variables also contains the influence of currency markets. We compute an index representing the evolution of the Swiss Franc with respect to a GDP-weighted basket of G7 currencies. Discussion of the effect of exchange rates on stock prices is contained e.g. in Jorion (1991).

The second group is composed of variables related to the general level of prices. We use two inflation measures: (1) the unexpected inflation rate which is computed using Kalman filters and (2) changes in expected inflation calculated as the difference between observed and unexpected inflation between period $t$ and period $t-1$. The effect of expected and unexpected inflation on stock prices are investigated and discussed by Fama and Schwert (1977) and Boudoukh and Richardson (1993).

The third group is related to general credit conditions in Switzerland and in the G7. We use variables that represent the default premium, i.e. the spread between risky debt (yield on corporate bonds) and riskless debt (yield on government bonds), and the term premium, i.e. the spread between long term and short term government bond yields. These variables are assumed to proxy for expected economic growth and represent the rate at which economic agents trade current consumption against future consumption (Harvey, 1991). The link between credit conditions and stock returns is described in Dahlquist and Harvey (2001). The last category relates to the evolution of the stock market. We use two alternative market indices: the Swiss and the World Datastream total return indices. These variables should be related to portfolio returns through the domestic or international versions of the CAPM.

\footnotetext{
${ }^{5}$ Data on Swiss industrial production are only available on a quarterly basis and therefore cannot be used in this study.
} 
The APT assumes that stock react to unanticipated news regarding macroeconomic and financial variables. Most of the literature has either considered rate of change models or autoregressive models. We follow Priestley (1996) in that we use Kalman filters to generate innovations from the original data series. The only exceptions are the stock market indices, where we use returns that are mostly considered to be unpredictable, and the changes in expected inflation.

\section{Results}

\subsection{Statistical APT}

We determine the relevant number of statistical factors by using the method developed by Connor and Korajczyk (1993). This is achieved by testing if the statistic described in equation (4) is significant using a t-test. Table 3 reports the values of this statistic for different numbers of factors. The only statistic which rejects the null hypothesis of a $K$-factor structure at a significance level of $5 \%$ is for $K=4$. Therefore, we consider that the relevant factor structure contains five factors.

\section{[Insert Table 3]}

Based on these results, we keep the first five factors from the Maximum Explanatory Component Analysis as the statistical factors driving Swiss stock returns. The first factor explains $52.33 \%$ of the variance, the second factor $6.46 \%$, the third $5.13 \%$, while the five synthetic variables together explain $72.31 \%$ of the variance of the industrial portfolio returns. We then perform FM two-pass tests to determine the risk premia on these five factors for each month of our test period (1991-2002). Table 4, Panel A presents the average risk premia of each statistical factor and their level of significance obtained using $\mathrm{GMM}^{6}$.

[Insert Table 4]

Our statistical model explains the cross-sectional returns well as the average adjusted $\mathrm{R}^{2}$ is equal to $18.66 \%$, and the average cross-sectional $\mathrm{R}^{2}$ is $40.17 \%$. These levels of explanatory power are high for cross-sections of stock returns. As the cross-sectional regressions are

\footnotetext{
${ }^{6}$ Similar significance levels are found when standard errors are corrected using Shanken's (1992) error-invariables method, and corrected for autocorrelation and heteroskedasticity using the Newey and West (1987) estimator.
} 
performed on portfolio excess returns, the constant term should be equal to zero. Table 4 indicates that the average intercept is close to zero and cannot be statistically distinguished from this value, which suggests that there is no omitted variable and that the sensitivities to the five factors are sufficient to explain excess returns.

As far as the factor risk premia are concerned, we note that one of them only (factor 3) is statistically significant at the $5 \%$ level. The fact that only one factor is significant could be due to there being positive and negative occurrences of the risk premia, with their average being not significantly different from zero. This is confirmed by the results obtained with our extension to the multi-factor setting of the Pettengill et al. (1995) method (described in 2.1). The results are displayed in Table 4, Panel B. We find that all risk premia are significant at the $5 \%$ level. We also find that all pairs of positive and negative risk premia are not significantly different from one another in absolute value. These results are a clear indication that a five-factor structure is required to characterize the returns on Swiss industrial portfolios as we conclude that there are significant relationships between the returns and the sensitivities to statistical factors. Our findings emphasize the importance of assessing separately the significance of the risk premia for positive and negative occurrences of the factors.

\subsection{Macroeconomic APT}

For the implementation of the macroeconomic version of the model, we also need to determine the relevant number of factors in a first stage. This is achieved by using the autoregressive test of Mei (1993) that is performed over the whole sample period (19862002). Table 5 contains the values of the statistic $\mathrm{L}_{K, K+1}$ that tests the null hypothesis that the generalized sum of squared residuals of a model with $K$ lags is equal to the generalized sum of squared residuals of a model with $K+1$ lags. The relevant number of factors is equal to $K+1$, with $K$ being the largest value for which the null hypothesis is rejected.

\section{[Insert Table 5]}

For the whole sample period, we find that four pre-specified factors are relevant. Based on this, we have to select four macroeconomic variables from our initial database. This is achieved using cluster analysis. We use the results of the cluster analysis at a level where the variables are gathered into four groups. The composition of these groups is given in Table 6 . To choose among the candidate variables in each of the four groups, we implement 168 
different macroeconomic models ${ }^{7}$. For each of these 168 alternatives, we run FM tests and select the best model according to the index $I$ that combines two measures of the explanatory power of the model, $I_{R^{2}}$, described in equation (5).

\section{[Insert Table 6]}

The final macroeconomic model is composed of the following variables: industrial production and changes in expected inflation in the G7 countries, as well as the Swiss term structure and the returns on the Swiss stock market. It is remarkable that these variables represent each of the four groups (level of economic activity, price levels, credit conditions, and stock market conditions) that we assumed to be important for the pricing of stocks. Two variables are related to global economic conditions and two variables pertain to the domestic economic environment. These results provide support for the hypothesis of partial integration of the Swiss stock market. Compared to the exogenously determined variables of Chen et al. (1986), our results provide a different perspective and show some overlap with their variables. However, our results highlight the importance of international factors for pricing the stocks in a small open economy.

The risk premia relative to these variables and their level of significance are presented in Table 7, Panel A. As for the statistical case, we find that the average intercept cannot be statistically distinguished from zero. None of the four macroeconomic variables appears to be significant over the entire sample. The explanatory power of the model is also quite high for the cross-section of stock returns as it amounts to an average $R^{2}$ of $30.41 \%$ (9.75\% in adjusted terms). It is slightly lower, however, than the average $R^{2}$ that is obtained for the statistical model.

\section{[Insert Table 7]}

As for the statistical model, we also distinguish between periods with positive and negative occurrences of the variables to further assess the link between portfolio returns and risk sensitivities. The results of these tests are presented in Table 7, Panel B. Contrary to what is the case with the statistical model, only two risk premia are statistically different from zero. These results may indicate that these macroeconomic innovations are only proxies for the underlying shocks that drive stock returns, despite the fact that our set of four variables obtained from a cluster analysis makes sense from an economic point of view. Another explanation for these results is that the variables which are used to construct innovations are

\footnotetext{
${ }^{7} 168$ corresponds to the number of different possible combinations of the variables $(6 \times 2 \times 2 \times 7)$.
} 
imperfect proxies for the evolution of true macroeconomic conditions due to the use of monthly data and to the unavoidable measurement errors.

\subsection{Comparison of models}

The above results suggest that a statistical model may be more appropriate in explaining equity returns. To test this assertion, we analyze the links between the risk premia of both types of models and compare their explanatory power. Table 8 provides the results, for each statistical factor, of a multiple regression of the statistical factor risk premia on the risk premia of the macroeconomic variables, while Table 9 presents the pairs of statistical and macroeconomic risk premia that exhibit the highest correlation. The risk premium on the most important statistical factor (i.e. factor 1) is strongly related to the Swiss stock market returns. The importance of the link between factor 1 and the Swiss stock market returns is confirmed by the high degree of correlation between their risk premia (0.66). In general, we observe that all of the statistical risk premia show significant links with at least one macroeconomic risk premium. Moreover, each macroeconomic risk premium has significant links with at least one statistical factor risk premium. These results indicate that the risk premia from both types of models are clearly linked. In addition, the $\mathrm{R}^{2} \mathrm{~s}$ of the four regressions in Table 8 are high as they range from $21 \%$ to $64 \%$. Nevertheless, the risk premia of statistical factors are influenced by other forces as well as the $\mathrm{R}^{2} \mathrm{~s}$ are not close to $100 \%$.

\section{[Insert Table 8]}

[Insert Table 9]

Formal comparisons of both models confirm the superiority of the statistical version of the model over the macroeconomic version. The result of the Wilcoxon signed-rank test is clearly in favor of the statistical model with a z-statistic equal to 2.5397 and a p-value close to zero (0.0111). This provides evidence that the statistical APT is superior to the macroeconomic APT in terms of the adjusted $R^{2}$. The same conclusions prevail when the Davidson and MacKinnon procedure (1981) is used. Indeed, the mean of the regression coefficient $\overline{\hat{\theta}}$ is equal to 0.62 and the value of the t-statistic testing the null hypothesis that $\overline{\hat{\theta}}=0.5$ is equal to 4.69 (significant at any level). This confirms that the cross-sections of returns forecasted from a statistical model have a better explanatory power than those forecasted from a macroeconomic model. 


\section{Concluding Remarks}

This paper provides an analysis of the determinants of stock returns in a small open economy in an APT framework. The empirical investigation is conducted for the Swiss stock market which has the particularity of including a large proportion of firms that are exposed to economic conditions prevailing outside the country as they sell and purchase their products and services overseas. As it is a developed market with no barriers to international investments, it could be considered as a market that is integrated with the rest of the world. However, this market has been found not to be integrated in previous literature. For this reason, we include both local and global variables in the set of potential macroeconomic explanatory variables. The global variables are aggregates constructed from countries of the G7, the main trade partners of Switzerland.

Two types of implementations of the model are investigated and compared: a statistical one and a macroeconomic one. We use monthly returns on 19 industrial sector portfolios over the period 1986-2002. The statistical implementation of the model yields five factors. The best macroeconomic version includes four variables, two of which are clearly linked to global economic conditions (innovations to G7 industrial production and changes in expected inflation) while two are linked to local factors (Swiss market return and innovations to the term structure). Interestingly, all belong to one of our four broad categories of variables: the general level of economic activity, price levels, credit conditions, and the stock market environment. These results confirm the identity of the relevant factors chosen by Chen et al. (1986) for the U.S. market, but emphasize the importance of international influences on the Swiss market.

The two-pass standard FM tests show that neither the statistical nor the macroeconomic versions displays significant relations between risk and return. However, when positive and negative realizations of the factors are taken into account, the risk-return relationship becomes highly significant for the statistical model, but only weakly for the macroeconomic model. This result clearly shows that the statistically determined factors yield a better representation of the determinants of stock returns than the macroeconomic variables. This is confirmed by formal comparisons of the explanatory power of both types of models. Finally, an analysis of 
the links existing between risk premia generated by the statistical model and those of the macroeconomic model shows that both types of premia are significantly related. However, the macroeconomic risk premia explain at best $65 \%$ of the variance of statistical risk premia, which suggests that other forces are at work. Their precise identification is left for further research.

This paper has important implications for both researchers and practitioners. From a research point of view, this paper stresses the urgent need to develop a theoretical model of asset pricing of partial integration that explicitly defines the level of integration of a market and determines the relevant set of variables to represent the sources of risk. From a practical point of view too, it has several implications. First, it shows that when managing a portfolio that includes Swiss equities, fund managers should not only take into account the sensitivity of stocks to the Swiss market, but also the sensitivities to innovations in the Swiss term structure, G7 industrial production and to changes in expected inflation in the G7. These factors should be borne in mind when devising hedging strategies. Second, when assessing the performance of a portfolio of Swiss stocks, the investors should take into account these additional risk factors. Finally, when selecting upon alternative investment projects, the calculation of the cost of capital for Swiss companies should consider these factors. Omitting these variables could yield seriously biased results and lead to erroneous investment decisions. 
Table 1: Measures of market openness

\begin{tabular}{lrrrrr}
\hline & $\begin{array}{r}\text { Market } \\
\text { Cap. }\end{array}$ & & Foreign Sales & \% Firms & \# Firms \\
& 16,635 & 0.29 & $10.19 \%$ & $31.43 \%$ & 6,068 \\
1. U.S. & 4,547 & 0.20 & $15.15 \%$ & $59.69 \%$ & 707 \\
2. Japan & 2,933 & 0.74 & $24.45 \%$ & $56.15 \%$ & 1,131 \\
3. U.K. & 1,475 & 0.56 & $36.96 \%$ & $77.67 \%$ & 430 \\
4. France & 1,432 & 0.65 & $35.00 \%$ & $76.19 \%$ & 420 \\
5. Germany & 801 & 0.86 & $32.41 \%$ & $58.15 \%$ & 227 \\
6. Canada & 728 & 0.56 & $32.22 \%$ & $65.69 \%$ & 137 \\
7. Italy & 695 & 1.31 & $58.31 \%$ & $95.90 \%$ & 122 \\
8. Netherlands & 693 & 0.98 & $50.76 \%$ & $81.76 \%$ & 148 \\
9. Switzerland & 609 & 2.89 & $52.88 \%$ & $91.59 \%$ & 321 \\
10. Hong Kong & 478 & 0.45 & $19.68 \%$ & $52.87 \%$ & 174 \\
11. Australia & 432 & 0.63 & $24.00 \%$ & $65.67 \%$ & 67 \\
12. Spain & 376 & 1.06 & $17.12 \%$ & $47.42 \%$ & 213 \\
13. Taiwan & 373 & 0.93 & $53.95 \%$ & $96.39 \%$ & 83 \\
14. Sweden & 349 & 0.77 & $56.36 \%$ & $94.03 \%$ & 67 \\
15. Finland & & & & & \\
\hline
\end{tabular}

Notes: Market capitalizations are from Dimson et al. (2002), the macroeconomic data from Datastream Thomson Financial and the quoted company data from Thompson Analytics. The data are for year 2000. "Market cap." gives the total market capitalizations in USD billion. " $(\mathrm{X}+\mathrm{M}) / \mathrm{Y}$ " is the ratio of the sum of exports and imports of a country divided by its GDP. "Average foreign sales" represents the average ratio of overseas sales divided by total sales of a company for firms in a given country. "\% firms" represents the percentage of firms that have sales abroad among the total number of companies in a country. "\# firms" indicates the number of firms for which data on foreign sales are available in each country. 


\section{Table 2: Summary statistics for the 19 industrial portfolios}

\begin{tabular}{|c|c|c|c|c|c|}
\hline & Industry & Mean & Std dev & Skewness & Kurtosi \\
\hline 1 & Building \& Construction Materials & 0.53 & 6.60 & -0.98 & 6.44 \\
\hline 2 & Diversified Industrials & 0.07 & 6.80 & -1.45 & 7.98 \\
\hline 3 & Electrical Equipment & 0.13 & 11.57 & -0.73 & 9.71 \\
\hline 4 & Engineering Contractors & 0.77 & 8.59 & -0.84 & 5.53 \\
\hline 5 & Engineering General & 0.26 & 7.19 & -1.27 & 7.52 \\
\hline 6 & Food Processors & 1.03 & 5.61 & 0.07 & 6.05 \\
\hline 7 & Pharmaceuticals & 1.24 & 5.64 & -0.99 & 6.84 \\
\hline 8 & Retailers Multi Department & -0.34 & 9.38 & -0.32 & 4.92 \\
\hline 9 & Hotels & 0.23 & 7.42 & -0.39 & 4.89 \\
\hline 10 & Education, Training & -0.17 & 13.20 & -1.36 & 7.18 \\
\hline 11 & Airlines \& Airports & -1.45 & 11.69 & -2.34 & 15.56 \\
\hline 12 & Food \& Drug Retailers & 0.49 & 7.91 & 0.06 & 7.92 \\
\hline 13 & Electricity & 0.59 & 4.28 & 0.30 & 6.30 \\
\hline 14 & Banks & 0.46 & 7.66 & -1.76 & 13.08 \\
\hline 15 & Insurance Non-Life & 0.33 & 6.82 & -0.54 & 9.29 \\
\hline 16 & Re-Insurance & 1.00 & 7.72 & -0.27 & 3.59 \\
\hline 17 & Other Insurance & 0.27 & 9.52 & -1.30 & 8.39 \\
\hline 18 & Investment Companies & 0.58 & 6.94 & -1.29 & 8.52 \\
\hline 19 & Miscellaneous & 0.35 & 6.42 & -2.59 & 15.97 \\
\hline
\end{tabular}

Notes: These statistics are computed from monthly continuously compounded returns of the sub-sector Datastream indices for Switzerland over the period 1986-2002. The mean and standard deviation are expressed in percentage per month. 


\section{Table 3: Test of the number of statistical factors}

\begin{tabular}{cc}
\hline Number of factors $\mathbf{K}$ & $\bar{\Delta}_{K, K+1}$ \\
\hline 1 & 3.01 \\
2 & 3.58 \\
3 & 1.54 \\
4 & $4.61^{*}$ \\
5 & 4.52 \\
6 & 2.96 \\
7 & 2.53 \\
8 & 0.96 \\
9 & 1.28 \\
10 & 2.51 \\
\hline
\end{tabular}

Notes: Each row gives the value of the Connor and Korajczyk (1993) test multiplied by 10,000 for the presence of a $K$-factor structure based on statistical factors. An * indicates that the null hypothesis of having $K$ factors is rejected at the $5 \%$ level. 
Table 4: Results of the cross-sectional tests of the statistical APT

Panel A : Average risk premia computed over the whole sample

\begin{tabular}{lcccccc}
\hline & Constant & Factor 1 & Factor 2 & Factor 3 & Factor 4 & Factor 5 \\
\hline Average risk premia & $1.66 \mathrm{E}-05$ & 0.0519 & 0.0477 & $-0.2658^{*}$ & -0.0421 & -0.1011 \\
\hline Adjusted $\mathrm{R}^{2}: 0.1866$ & $\mathrm{R}^{2}: 0.4017$ & & & & &
\end{tabular}

Panel B :Average risk premia for positive and negative realizations of the factor

\begin{tabular}{lccccc}
\hline & Factor 1 & Factor 2 & Factor 3 & Factor 4 & Factor 5 \\
\hline Positive factor realization & $0.3817^{*}$ & $0.7436^{*}$ & $0.3674^{*}$ & $0.5666^{*}$ & $0.5157^{*}$ \\
Negative factor realization & $-0.5142^{*}$ & $-0.6677^{*}$ & $-0.6131^{*}$ & $-0.7038^{*}$ & $-0.6685^{*}$ \\
Risk premia difference & -0.1325 & 0.0759 & -0.2457 & -0.1372 & -0.1528
\end{tabular}

Notes: This table provides the average risk premia of the cross-sectional regression for the statistical model. Panel A gives the average risk premia (in percent per month) for the monthly regressions over the whole sample period 1991-2002. Panel B separates the periods where the factor realization are positive from those where there are negative. An $*$ indicates that the average risk premium is significant at the $5 \%$ level, whereas an would indicate that the difference between positive and negative risk premia is significant at the $5 \%$ level. 
Table 5: Test of the number of macroeconomic factors

\begin{tabular}{cc}
\hline Number of lags $\boldsymbol{K}$ & $\mathbf{L}_{\boldsymbol{K}, \boldsymbol{K}+\boldsymbol{1}}$ \\
\hline 6 & 23.65 \\
5 & 151.71 \\
4 & 160.68 \\
3 & $479.97^{*}$ \\
2 & $415.24^{*}$ \\
1 & $704.49^{*}$ \\
\hline
\end{tabular}

Notes: This table provides the results of the Mei (1993) statistic that looks for the optimal number of macroeconomic variables necessary to explain the portfolio returns. The null hypothesis is that there is no difference between the generalized sum of squares of a model with $K$ lags and $K+1$ lags. An * indicates that the null hypothesis is rejected at the $5 \%$ level. The test is performed over the period 1986-2002.

Table 6: Cluster analysis results

\begin{tabular}{cc}
\hline Group & $\begin{array}{c}\text { Final } \\
\text { composition }\end{array}$ \\
\hline $\mathbf{1}$ & UNP-CH \\
& RTL-CH \\
& UI-CH \\
& CEI-CH \\
& INP-G7 \\
& UI-G7 \\
\hline $\mathbf{2}$ & EXP-CH \\
& CEI-G7 \\
\hline $\mathbf{3}$ & DEF-CH \\
& TRM-CH \\
\hline $\mathbf{4}$ & BRENT \\
& DEF-G7 \\
& TRM-G7 \\
& MKT-CH \\
& MKT-W \\
& UNP-G7 \\
& FX-G7
\end{tabular}

Notes: This table provides the results of an agglomerative hierarchical cluster algorithm. The results are those of a four group structure. The abbreviations represent the following variables. UNP: unemployment, RTL: retail sales, UI: unexpected inflation, CEI: changes in expected inflation, INP: industrial production, EXP: exports, DEF: default premium, TRM: term premium, BRENT: Brent oil prices, MKT: market returns, FX: foreign exchange index, $\mathrm{CH}$ : Switzerland, G7: G7 countries, W: World. UNP, INP, RTL and EXP are adjusted for seasonality. RTL, INP and EXP are expressed in real terms. All variables are innovations, except CEI and MKT. 
Table 7: Results of the cross-sectional tests of the macroeconomic APT

Panel A : Average risk premia computed over the whole sample

\begin{tabular}{lccccc}
\hline & Constant & INP-G7 & CEI-G7 & TRM-CH & MKT-CH \\
\hline Average risk premia & 0.0049 & 0.0012 & 0.0004 & -0.1466 & -0.0014 \\
\hline
\end{tabular}

Adjusted $R^{2}: 0.0975 \quad R^{2}: 0.3041$

Panel B :Average risk premia for positive and negative realizations of the variables

\begin{tabular}{lcccc}
\hline & INP-G7 & CEI-G7 & TRM-CH & MKT-CH \\
\hline Positive variable realization & 0.0024 & $0.0009^{*}$ & -0.2299 & $0.0218^{*}$ \\
Negative variable realization & -0.0002 & $-5.35 \mathrm{E}-05$ & -0.0483 & -0.0479 \\
Risk premia difference & 0.0022 & $8.73 \mathrm{E}-04$ & -0.2782 & -0.0261
\end{tabular}

Notes: This table provides the average risk premia of the cross-sectional regression for the macroeconomic implementation of the model. Panel A gives the average risk premia (in percent per month) for the monthly regressions over the whole sample period 1991-2002. Panel B separates the periods where the observed macroeconomic variables are positive from those where there are negative. An * indicates that the average risk premium is significant at the $5 \%$ level, whereas an would indicate that the difference between positive and negative risk premia is significant at the $5 \%$ level. The abbreviations represent the following variables. CEI: changes in expected inflation, INP: industrial production, TRM: term premium, MKT: market returns, $\mathrm{CH}$ : Switzerland, G7: G7 countries. 
Table 8: Determinants of statistical factor risk premia

\begin{tabular}{lllccc}
\hline & INP-G7 & CEI-G7 & TRM-CH & MKT-CH & $\mathrm{R}^{2}$ \\
\cline { 2 - 6 } Factor 1 & -6.39 & 34.33 & 0.08 & $12.03^{*}$ & 0.64 \\
Factor 2 & $35.41^{*}$ & $71.22^{*}$ & 0.00 & -0.83 & 0.49 \\
Factor 3 & -2.84 & -24.96 & 0.09 & $-5.37^{*}$ & 0.21 \\
Factor 4 & -9.21 & $69.81^{*}$ & $0.15^{*}$ & $-3.40^{*}$ & 0.28 \\
Factor 5 & $-14.83^{*}$ & $-55.91^{*}$ & 0.11 & $5.11^{*}$ & 0.32 \\
\hline
\end{tabular}

Notes: This table shows the regression coefficient of factor risk premia on the macroeconomic variables risk premia as well as the $\mathrm{R}^{2}$ from these regressions over the period 1991-2002 (144 observations). An * indicates that the coefficient is significant at the $5 \%$ level. The abbreviations represent the following variables. CEI: changes in expected inflation, INP: industrial production, TRM: term premium, MKT: market returns, CH: Switzerland, G7: G7 countries. 
Table 9: Correlation analysis of risk premia

\section{Panel A: Highest correlation with statistical risk premia}

\begin{tabular}{ccc}
\hline $\begin{array}{c}\text { Statistical } \\
\text { Factor }\end{array}$ & $\begin{array}{c}\text { Macroeconomic } \\
\text { variable }\end{array}$ & $\begin{array}{c}\text { Coefficient of } \\
\text { correlation }\end{array}$ \\
\hline Factor 1 & MKT-CH & $0.66^{*}$ \\
Factor 2 & INP-G7 & $0.49^{*}$ \\
Factor 3 & INP-G7 & -0.11 \\
Factor 4 & CEI-G7 & $0.27^{*}$ \\
Factor 5 & MKT-CH & $0.21^{*}$ \\
\hline
\end{tabular}

\section{Panel B: Highest correlation with macroeconomic risk premia}

\begin{tabular}{ccc}
\hline $\begin{array}{c}\text { Macroeconomic } \\
\text { variable }\end{array}$ & $\begin{array}{c}\text { Statistical } \\
\text { Factor }\end{array}$ & $\begin{array}{c}\text { Coefficient of } \\
\text { correlation }\end{array}$ \\
\hline INP-G7 & Factor 2 & $0.49^{*}$ \\
CEI-G7 & Factor 2 & $0.29^{*}$ \\
TRM-CH & Factor 5 & 0.12 \\
MKT-CH & Factor 1 & $0.66^{*}$ \\
\hline
\end{tabular}

Panel A presents the macroeconomic variables which risk premia is the most highly correlated with the risk premia of the different statistical factors. Panel B presents the statistical factors which risk premia is the most highly correlated with the risk premia of the different macroeconomic variables. These figures are computed over the period 1991-2002 (144 observations). An * indicates that the correlation coefficient is significant at the $5 \%$ level. The abbreviations represent the following variables. CEI: changes in expected inflation, INP: industrial production, TRM: term premium, MKT: market returns, CH: Switzerland, G7: G7 countries. 


\section{REFERENCES}

Antoniou, A., Garrett, I., \& Priestley, R. (1998). Macroeconomic variables as common persuasive risk factors and the empirical content of the arbitrage pricing theory. Journal of Empirical Finance 5(3), 221-240.

Beckers, S., Cummins, P., \& Woods, C. (1993). The estimation of multiple factor models and their applications: the Swiss equity market. Financial Markets and Portfolio Management 7(1), 24-45.

Bekaert, G., \& Harvey, C. R. (1995). Time-varying world market integration, Journal of Finance 50(2), 403-444.

Bilson, C. M., Brailsford, T. J., \& Hooper, V. J. (2001). Selecting macroeconomic variables as explanatory factors of emerging stock market returns. Pacific-Basin Finance Journal 9(4), 401-426.

Boudoukh, J., \& Richardson, M. (1993). Stock returns and inflation: a long-horizon perspective. American Economic Review 83(5), 1346-1355.

Brennan, M. J., Chordia, T., \& Subrahmanyam, A. (1998). Alternative factor specifications, security characteristics and the cross-section of expected stock returns. Journal of Financial Economics 49(3), 345-373.

Broillet, P. (1991). Spécification empirique des facteurs de l'APT sur le marché suisse des actions. Swiss Journal of Economics and Statistics 127(3), 491-510.

Chen, N. F., Roll, R., \& Ross, S. A. (1986). Economic forces and the stock market. Journal of Business 59(3), 383-403.

Chen, S. J., \& Jordan, B. D. (1993). Some empirical tests in the arbitrage pricing theory: macrovariables vs. derived factors. Journal of Banking and Finance 17(1), 65-89.

Chen, S. J., Hsieh, C, \& Jordan, B. D. (1997). Real Estate and the arbitrage pricing theory : macrovariables vs. derived Factors. Real Estate Economics 25(3), 505-523.

Clare, A. D., \& Priestley, R. (1998). Risk factors in the Malaysian stock market. Pacific-Basin Finance Journal 6(1-2), 103-114.

Clare, A. D., \& Thomas, S. H. (1994). Macroeconomic factors, the APT and the UK stock market. Journal of Business Finance and Accounting 21(3), 309-330.

Connor, G., \& Korajczyk, R. A. (1993). A test for the number of factors in an approximate factor model, Journal of Finance 48(4), 1263-1291.

Cooper, I., A., \& Kaplanis, E. (2000). Partially segmented international capital markets and international capital budgeting. Journal of International Money and Finance 19(3), 309-323. 
Cuenot, E., \& Reyes, C. (1992). Multi-factor APT model for the Swiss equity market. , Zurich: Credit Suisse Investment Research Basic Report.

Dahlquist, M., \& Harvey, C. R. (2001). Global tactical asset allocation. Emerging Markets Quarterly (Spring), 6-14.

Davidson, R., \& MacKinnon, J. (1981). Several tests for model specification in the presence of alternative hypotheses. Econometrica 49(3), 781-793.

Dimson, E., Marsh, P., \& Staunton, M. (2002). Triumph of the Optimists. , Princeton and Oxford: Princeton University Press.

Elsas, R., El-Shaer, M., \& Theissen, E. (2003). Beta and returns revisited - Evidence from the German stock market. Journal of International Financial Markets, Institutions and Money 13(1), 1-18.

Errunza, V., \& Losq, E. (1985). International asset pricing under mild segmentation: theory and tests. Journal of Finance 40(1), 105-124

Fama, E. F. (1981). Stock returns, real activity, inflation and money. American Economic Review 71(4), 545-565.

Fama, E. F., \& French K. R. (1992) The cross-section of expected stock returns, Journal of Finance 47(2), 427-465.

Fama, E. F., \& MacBeth, J. D. (1973). Risk, return and equilibrium: empirical tests, Journal of Political Economy 81(3), 607-636.

Fama, E. F., \& Schwert, W. G. (1977). Asset returns and inflation. Journal of Financial Economics 5(2), 115-145.

Fedorov, P., \& Sarkissian, S. (2000). Cross-sectional variations in the degree of global integration: the case of Russian equities. Journal of International Financial Markets, Institutions and Money 10(2), 131-150.

Ferson, W. E., \& Harvey, C. R. (1994). Sources of risk and expected returns in global equity markets, Journal of Banking and Finance 18(4), 775-803.

Fletcher, J. (1997). An examination of the cross-sectional relationship of beta and return: UK evidence. Journal of Economics and Business 49(3), 211-221.

Gallati, R. R. (1993). Empirical application of APT multi-factor models to the Swiss equity market. Zurich: Credit Suisse Investment Research Basic Report.

Griffin, J. M., \& Karolyi, A. G. (1998). Another look at the role of the industrial structure of markets for international diversification strategies. Journal of Financial Economics 50(3), 351-373.

Griffin, J. M., \& Stulz, R. M. (2001). International competition and exchange rate shocks: a cross-country industry analysis of stock returns. Review of Financial Studies 14(1), 215-241. 
Groenewold, N., \& Fraser, P. (1997). Share prices and macroeconomic factors. Journal of Business Finance \& Accounting 24(9/10), 1367-1383.

Groenewold, N., \& Fraser, P. (2001). Test of asset-pricing models : how important is the iidnormal assumption? Journal of Empirical Finance 8(4), 427-449.

Hamao, Y. (1988). An empirical examination of the arbitrage pricing theory: using Japanese data. Japan and the World Economy 1(1), 45-61.

Hardouvelis, G., Malliaropoulos, D., \& Priestley, R. (2002). The impact of globalization on the equity cost of capital. Working paper, Norwegian School of Management, Sandvika (Norway).

Harvey, C. (1991). The term structure and World economic growth, Journal of Fixed Income $1(1), 4-17$.

Heston, S. L., \& Rouwenhorst, K. G. (1994). Does industrial structure explain the benefits of international diversification? Journal of Financial Economics 36(1), 3-27.

Heston, S. L., Rouwenhorst, K. G., \& Wessels, R. E. (1995). The structure of international stock returns and the integration of capital markets. Journal of Empirical Finance 2(3), 173197.

Hietala, P. T. (1989). Asset pricing in partially segmented markets: evidence from the Finnish stock markets. Journal of Finance 44(3), 697-718.

Hodoshima, J., Garza-Gómez, X., \& Kunimura, M. (2000). Cross-sectional regression analysis of return and beta in Japan. Journal of Economics and Business 52(6), 515-533.

Isakov, D. (1999). Is beta still alive? Conclusive evidence from the Swiss stock market. European Journal of Finance 5(3), 202-212.

Jorion, P. (1991). The pricing of exchange risk in the stock market. Journal of Financial and Quantitative Analysis 26(3), 363-376.

Kaneko, T., \& Lee, B.-S. (1995). Relative importance of economic factors in the US and Japanese markets. Journal of the Japanese and International Economies 9(3), 290-307.

Karolyi, A. G., \& Stulz, R. M. (2003). Are financial assets priced locally or globally? In G. Constantinides, M. Harris, \& R. M. Stulz (Eds.), Handbook of the Economics of Finance Amsterdam: North Holland.

Korajczyk, R. A., \& Viallet, C. J. (1989). An empirical investigation of international asset pricing, Review of Financial Studies 2(4), 553-585.

Kryzanowski, L., \& Zhang, H. (1992). Economic forces and seasonality in stock returns. Review of Quantitative Finance and Accounting 2, 227-244. 
Lehmann, B. N., \& Modest, D. M. (1988). The empirical foundations of the arbitrage pricing theory. Journal of Financial Economics 21(1), 213-254.

Lewis, K. K. (1999). Trying to explain home bias in equities and consumption. Journal of Economic Literature 37(2), 571-608.

Martikainen, T., Yli-Olli, P., \& Gunasekaran, A. (1991). Incremental significance of prespecified macroeconomic factors in testing the arbitrage pricing theory: empirical evidence with Finnish data. Applied Financial Economics 1(3), 139-147.

Mei, J. (1993). Explaining the cross-section of returns via a multi-factor APT model. Journal of Financial and Quantitative Analysis 28(3), 331-345.

Merville, L. J., Hayes-Yelken, S., \& Xu, Y. (2001). Identifying the factor structure of equity returns. Journal of Portfolio Management 27(4), 51-62.

Newey, W., \& West, K. (1987). A simple positive semi-definite, heteroskedasticity and autocorrelation consistent covariance matrix. Econometrica 55(3), 703-708.

Pettengill, G. N., Sundaram, S., \& Mathur, I. (1995). The conditional relation between beta and returns. Journal of Financial and Quantitative Analysis 30(1), 101-116.

Priestley, R. (1996). The arbitrage pricing theory, macroeconomic and financial factors, and expectations generating processes. Journal of Banking \& Finance 20(5), 869-890.

Rendu de Lint, C. (2002). Risk profiles: how do they change when stock markets collapse? Journal of International Financial Markets, Institutions and Money 12(1), 59-80.

Schwert, W. G. (1990). Stock returns and real activity: a century of evidence. Journal of Finance 45(4), 1237-1257.

Shanken, J. (1992). On the estimation of beta-pricing models. Review of Financial Studies 5(1), 1-34.

Vessereau, T. P. R. (2000). Etude du MEA sur le marché des actions suisses. Working paper no 2000s-44, Cirano, Montréal.

Wei, K. C. J. (1988). An asset-pricing theory unifying the CAPM and APT. Journal of Finance 43(4), 881-892.

$\mathrm{Xu}$, Y. (2003). Extracting factors with maximum explanatory power. Working paper, University of Texas, Dallas.

Yli-Olli, P., \& Virtanen, I. (1992). Some empirical tests of the theory of arbitrage pricing using transformation analysis. Empirical Economics 17(4), 507-522.

Zhou, G. (1999). Security factors as linear combinations of economic variables. Journal of Financial Markets 2(4), 403-432. 